\title{
SiCTiC as catalyst support for HT-PEMFCs. Influence of Ti content.
}

\author{
H. Zamora, J. Plaza, P. Velhac, P. Cañizares, M.A. Rodrigo, J. Lobato \\ Department of Chemical Engineering. Faculty of Chemical Science \& Technology. \\ University of Castilla La Mancha. Campus Universitario n12. 13071 Ciudad Real. \\ SPAIN
}

\begin{abstract}
This manuscript studies the influence of the titanium content on the main physicochemical properties of a binary silicon carbide- titanium carbide raw material (SiCTiC), to be used as catalyst support in High Temperature PEM fuel cells (HTPEMFCs). Three SiCTiC samples with 10, 20 and 30\% TiC molar content were studied, analysing the most relevant parameters to be used as catalyst support. First, BET surface area, electrical conductivity, thermal resistance in hot acidic media, and electrochemical resistance were the parameters studied. Results achieved show a decreasing of the BET surface area with the increasing of TiC content, but also a enhancement of the electrical conductivity. All materials studied demonstrated high thermal and electrochemical resistance. After the preliminary physicochemical characterization, Pt-based catalysts with a $40 \%$ wt. metal content were synthesized using different carbides studied. Platinum particle and crystallite size, real platinum content and distribution, and electrochemical surface area (ECSA) were the parameters studied. SiCTiC with $30 \% \mathrm{Pt}$ content exhibited a poor Pt dispersion and ECSA value, achieving better results with catalysts prepared using SiCTiC supports with lower Ti content, resulting on good candidates to be used in this kind of technology.
\end{abstract}

\section{Keywords:}

Binary silicon titanium carbide, vulcan carbon, high temperature PEM fuel cells. 


\section{Introduction}

Proton Exchange Membrane Fuel Cells (HTPEMFCs) are devices that use the electrochemical energy contained in Hydrogen and a comburent, usually air or oxygen, to produce hot water and energy, making these systems more environmentally sustainable than conventional fossil fuel engines [1]. Specially, High temperature PEMFCs have received much attention in the last years, due to its many benefits respect to low temperature fuel cell devices (better kinetics on the cathode reaction, improving of water and heat management, and better tolerance to the catalyst poisoning agents contained in the feed flow, such as carbon monoxide).

The development of new catalysts is one of the most interesting points in the improvement of HT-PEMFCs, focusing the study in two concrete fields: the reduction of the Platinum amount, which supposes a considerably decreasing of the production costs and new catalyst supports, to achieve enhanced service lifetime and performance. These new catalysts supports are expected to avoid rapid degradation of the catalyst, due to the hot acidic environment of the fuel cell and the support corrosion attributed to the high voltages achieves in the start-up and turn down processes [2].

Carbonaceous supports, especially Vulcan Carbon, are the typical catalyst support used, because it presents low cost, exhibit suitable electrical properties and has a high BET surface area, which favors a better dispersion of platinum during the preparation of the catalyst. However, in terms of durability, these material present important disadvantages related to its poor electrochemical, thermal and chemical resistance in the aggressive operational conditions of the HT-PEMFC mentioned above [2-3]. On one hand, the hot acidic media promotes carbon corrosion, which is further related to a decrease in the mechanical and electrochemical properties of the catalyst. Furthermore, the degradation of the catalyst support enhances the agglomeration of the Pt catalyst particles, reducing 
the active area and the performance of the catalyst. On the other hand, carbon corrosion starts to appear at potentials over $0.267 \mathrm{~V}$ vs RHE, resulting in a several corrosion at voltages over $1.2 \mathrm{~V}$. These high values are present at lower current densities and open circuit voltage (OCV) conditions [2]. This fact leads to losses on the electroactive surface area and activity during operation of a fuel cell and they mean lower durability and worse performance of the HTPEMFC [4-5].

Considerable research efforts have focused on the search of alternative catalyst supports. The target properties are: high electrical conductivity to assure the electron transfer, high surface area to provide a high dispersion of platinum nanoparticles, and good corrosion resistance under oxidizing conditions [6]. Recently, some novel ceramic materials, such as Tungsten Carbide [4], Titanium-based materials [8-10], or Silicon carbide [7, 11-13] have been evaluated as catalyst support looking for an improvement service lifetime of the catalytic layer. Results obtained are promising [7- 10], and they are related to their high chemical and oxidation stability and the excellent mechanical properties and thermal resistance [7, 13].

A novel binary silicon-titanium carbide ( $\mathrm{SiCTiC}$ ) material was tested by our research group formerly, with promising results [14] to be used as catalyst support. But SiCTiC exhibited moderate electrical conductivity and porosity, which means that this material must be improved in order to achieve its best performance. In this work, the influence of the $\mathrm{TiC}$ content $(10,20$ and $30 \% \mathrm{~mol}$. TiC content) on the main physicochemical properties of the novel SiCTiC has been evaluated.

\section{Experimental}


2.1 Physicochemical analysis

X-Ray diffraction (XRD) measurements were carried out in a Philips PW- 1700 diffractometer with rotating anode, applying the copper transition constant for each sample. Measurements of $2 \theta$ angle were located between $0^{\circ}$ and $90^{\circ}$ with a sweep speed of $0,1^{\circ} 2 \theta / \mathrm{s}$. XRD parameters were calculated using Scherrer (1) and Bragg (2) equations:

$$
\begin{aligned}
& \mathrm{L}_{\mathrm{C}}=\frac{0,89 \cdot \lambda}{\mathrm{B} \cdot \cos (\theta)} \\
& \mathrm{d}_{002}=\frac{\lambda}{2 \cdot \sin (\theta)}
\end{aligned}
$$

Where $L c$ is the crystal size in $\mathrm{nm}, d_{002}$ is the distance between planes (nm), $\lambda$ corresponds to the $K \alpha$ radiation of copper $(\lambda=0.15418 \mathrm{~nm}), B$ is a parameter related to the the full width at half maximum intensity of the peak, and $\theta$ is the angle corresponding to $I_{\max }(\mathrm{rad})$.

BET surface area of different samples and total pore volume were obtained using $\mathrm{N}_{2}$ adsorption-desorption method at $77 \mathrm{~K}$ using a QUANTACHROME device, model QUADRASORB 3SI.

In order to get more information about the main physicochemical properties of the materials as catalyst support and microporous layers (MPLs), different electrodes were prepared using a commercial Toray Carbon paper with 10\% PTFE content (Fuelcellstore, Texas, USA) as electrode GDL, and depositing the different MPLs based on the different SiCTiC materials. These layers were deposited as inks by airbrushing method, using isopropanol as solvent and 10\% PTFE, to achieve a concentration of 4 $\mathrm{mg} / \mathrm{cm}^{2}$ on SiCTiC raw material. After that, electrodes were thermally treated in a 
furnace at $360^{\circ} \mathrm{C}$ during $30 \mathrm{~min}$, in order to evaporate the solvent and PTFE sintering process.

Electrical longitudinal conductivity was calculated using a four-point system, consisting in a basic device of two PTFE plates of $2 \times 8 \mathrm{~cm}^{2}$ and $1 \mathrm{~cm}$ thickness on which rectangular $5 \times 1 \mathrm{~cm}$ electrodes are disposed, two gold wires are placed on both ends of the electrode to apply the electrical current, and two others gold wires in the centre of the electrode used to measure the potential difference. Electrical resistivity of each electrode was determined by spectroscopy impedances performed at 125, 150 and $175^{\circ} \mathrm{C}$, using a potentiostat/galvanostat AUTOLAB PGSTAT 30 with the working module FRA (Frequency Response Analysis). Resistivity of each sample (in ohms) was measured using a frequency interval between 10000 and $0.1 \mathrm{~Hz}$, applying a potential difference of $0 \mathrm{~V}$ and amplitude of $0,01 \mathrm{~V}$. Conductivity of each sample was determined from resistivity values, using the equation (3).

$$
C=\frac{L}{R . S}[3]
$$

Where $\mathrm{C}$ is the electrical conductivity $(\mathrm{S} / \mathrm{cm}), \mathrm{L}$ is the distance between the sensor and reference gold wires $(1 \mathrm{~cm}), \mathrm{R}$ is the ohmic resistance $(\Omega)$, calculated from the spectroscopy impedance analysis, and $\mathrm{S}$ is the transversal section of the sample, calculated using the thickness and the width $(1 \mathrm{~cm})$ of the electrodes.

Thermal resistance in hot acidic media was evaluated placing $1 \mathrm{~cm}^{2}$ electrode samples, impregnated with $13 \mathrm{mg}$ concentrated phosphoric acid in a furnace for 8 hours at $185^{\circ} \mathrm{C}$. Electrodes were analysed with XRD before and after the process in order to observe changes in the crystallinity of the samples which indicate degradation of the material. 
The electrochemical stability of the different $\mathrm{SiCTiC}$ was evaluated by a voltammetric test in a half cell system with $2 \mathrm{M} \mathrm{H}_{3} \mathrm{PO}_{4}$ media using $1.5 \mathrm{~cm}$ diameter electrodes with the different carbides as working electrodes, and a gold sheet as counter electrode, performing 350 cycles to each samples at $20 \mathrm{mV} / \mathrm{s}$ scan rate, from -0.21 to $0.79 \mathrm{~V}$ vs $\mathrm{Ag} / \mathrm{AgCl}$ reference electrode. Nitrogen was bubbled to the aqueous media in order to remove the oxygen of the system.

\subsection{Catalyst synthesis and characterization}

Different catalysts were prepared by the following method, using the different SiCTiC samples as catalyst support. The process consists in preparing 500mg of each different catalyst with a $40 \%$ mass percentage platinum deposit on each support. The Chloroplatinic Acid Hexahydrate is used as precursor salt because of its good solubility.

Synthesis was carried out in $500 \mathrm{~mL}$ of $0.1 \mathrm{M}$ formic acid solution at $80{ }^{\circ} \mathrm{C}$ with stirring. Support was added during the heating phase to insure a homogeneous mix and to obtain a better platinum dispersion on the support. When the temperature reached 80 ${ }^{\circ} \mathrm{C}$, the precursor salt solved in deionized water was added slowly drop by drop during 15 minutes approx. in order to improve the dispersion of the platinum in the media, and reaction was conducted with stirring and heating during one hour more. After that, solution was filtered, and the solid was dried in a furnace for 6 hours at least, in order to remove the solvent. The final dry catalysts obtained were weighted and characterized.

Real platinum content was determined by ICP analysis, using a Varian Liberty RL sequential ICP-AES multielemental analysis device. Solid samples were subjected to acid digestion process using $3 \mathrm{ml}$ of $\mathrm{HF}, 2 \mathrm{ml}$ of $\mathrm{HCl}$ and $2 \mathrm{ml}$ of $\mathrm{H}_{2} \mathrm{O}_{2}$, in order to solve the metals contained in the sample. 
Platinum dispersion of the catalysts was analysed by TEM micrographs, using a Jeol 2100 , working at $200 \mathrm{kV}$, with a double-twist sample holder, $\left( \pm 30^{\circ}\right)$ and EDS (Oxford Link). Samples were dispersed in acetone media, and a drop of sample was deposited on a copper rack, covered with perforated C (holey carbon, EMS).

Temperature Programmed Reduction (TPR) experiments were carried out in a Micromeritics AutoChem Hp Chemisorption Analyzer. Approximately, 0,1g of fresh catalyst powder was loaded into the device, applying a constant flow of $20 \mathrm{ml} \mathrm{min}^{-1}$ of Argon with 5\% wt. $\mathrm{H}_{2}$ content. The temperature was increased from room temperature to $900{ }^{\circ} \mathrm{C}$ applying a constan rate of $5{ }^{\circ} \mathrm{C} \mathrm{min}^{-1}$. Hydrogen consumed was determined trhough a termal conductivity cell (TCD). Finally, the electrochemical stability of the different SiCTiC based catalyst was also evaluated using the same half-cell system used in the support characterization. Aqueous media was $2 \mathrm{M} \mathrm{H}_{3} \mathrm{PO}_{4}$ at $50{ }^{\circ} \mathrm{C}$, in order to accelerate the electrochemical degradation of the catalyst and also to improve the gaseous $\mathrm{O}_{2}$ removal, using $\mathrm{N}_{2}$ gas such as during the support measurements. In these conditions, 400 cycles were performed to each sample at $50 \mathrm{mV} / \mathrm{s}$ scan rate, from -0.21 to $1.00 \mathrm{~V}$ vs $\mathrm{Ag} / \mathrm{AgCl}$ reference electrode. The degradation of the catalysts was studied by the decreasing of the electrochemical surface active area (ECSA), calculated through the $\mathrm{H}_{2}$ absorption/desorption peaks, using the equation (4) [15]:

$$
\operatorname{ECS} A=\frac{A_{(P t)}}{v \times C} \times \frac{1}{L}
$$

Where ECSA is the Electrochemical Surface Area $\left(\mathrm{m}^{2} \mathrm{~g}^{-1} \mathrm{Pt}^{-1}\right), A_{P t}$ is the surface under the hydrogen desorption peak $\left(\mathrm{AV} \mathrm{cm}{ }^{-2}\right), \mathrm{v}$ is the scan rate $\left(\mathrm{V} \mathrm{s}^{-1}\right), C$ is a constant related to the required load to reduce the proton layer on the active platinum $\left(0.21 \mathrm{mC} \mathrm{cm}^{-2}\right)$ and $L$ is the Platinum load in the catalyst layer $\left(0.3 \mathrm{mg}(\mathrm{Pt}) / \mathrm{cm}^{-2}\right)$. 


\section{Results and discussion}

\subsection{Physicochemical analysis}

SiCTiC powders with different TiC molar contents of 10, 20 and 30\% were provided commercially by SICAT Company (París, France). It must be pointed that SiCTiC is not a physical mixture of both carbides, but a compound obtained from Si and Ti source, obtaining a product with zones rich in $\mathrm{SiC}$ and other in $\mathrm{TiC}$, with an interstitial material between the grains formed by diffusion of the $\mathrm{SiC}$ and $\mathrm{TiC}$ grains. Figure 1 shows the XRD obtained for all powders tested.

\section{Figure 1 Here}

Peaks located at $2 \theta$ values of $35.541 .3^{\circ}, 60^{\circ}$, and $71.7^{\circ}$ approx. which correspond to (111), (200), (311) and (222) planes of $\mathrm{SiC}$ respectively confirm the presence of of $\beta$-SiC (cubic structure) in the different binary carbides. Respect to the $\mathrm{TiC}$, the main characteristic diffraction peaks appears at $2 \theta$ values of $35.9^{\circ}(111)$ plane, $41.7^{\circ}(200)$ plane, $60.45^{\circ}(220)$ plane, $72.4^{\circ}(311)$ plane, and $76.1^{\circ}(222)$ plane, which correspond to the fcc cubic structure [16]. The main diffraction peak for $\mathrm{SiC}$ and $\mathrm{TiC}$ are found at $35.5^{\circ}$ and $41.7^{\circ}$ respectively This fact is confirmed since the higher is the TiC molar content on the SiCTiC sample, the higher is the intensity of these both peaks and smaller is the main peak attributed to SiC (located at $2 \theta=35.5^{\circ}$ ). The influence of the TiC content on the crystallite properties of the binary carbide material is confirmed by the differences found on the peaks located at $35.5^{\circ}$ and $72^{\circ}$ ( $\mathrm{SiC}$ main peaks), and $41^{\circ}$ and $76^{\circ}$ (TiC main peaks) when the different diffractograms are compared $[14,16]$. Crystallite size and distance between planes for the main peak of the $\operatorname{SiC}\left(2 \theta=36^{\circ}\right)$ were calculated using the equations 1 and 2 , showed in the experimental section of this document. In order to know more 
characteristics of the raw powders, they were subjected to BET analysis. Table 1 shows the most relevant crystallite and BET acquired data of the different powder samples.

\section{Table 1 Here}

As it can be observed, the higher is the TiC content, the lower is the BET surface area and the pore volume of the $\mathrm{SiCTiC}$, which means that $\mathrm{TiC}$ exhibit a very low porosity structure. Microporosity values are affected in the same way with the increasing of the TiC molar content on the binary carbide. The crystallite properties shown in Table $1\left(\mathrm{~L}_{c}\right.$ and $\left.\mathrm{d}_{002}\right)$ were calculated for faces $\left(\begin{array}{lll}1 & 1 & 1\end{array}\right)(\mathrm{SiC})$ and $\left(\begin{array}{lll}2 & 0 & 0\end{array}\right)(\mathrm{TiC})$, respectively, since these both peaks are not influenced by other nearby peaks, which could affect to the obtained values of the crystallite parameters [14]. Results show that both carbides present similar crystal size, around $20 \mathrm{~nm}$. SiC crystal size does not show a clear tendency on the crystal size variation with the amount of $\mathrm{TiC}$, but in the case of titanium carbide, the crystallite size increases with the \% $\mathrm{TiC}$ in the sample. Respect to the distance between planes, all samples show the same range value for both carbides, being slightly lower in the case of the $\mathrm{TiC}$, which means that $\mathrm{TiC}$ exhibit a more crystalline structure than $\mathrm{SiC}$, which could explain the reduction of the BET area values in the binary carbides with higher amounts of TiC.

Electrodes with micro porous layers (MPLs) prepared with the SiCTiC samples with different $\mathrm{SiC}: \mathrm{TiC}$ molar ratio were prepared according to the procedure described in experimental section, in order to evaluate the rest of electrochemical properties of the materials. Figure 2 shows the electrical conductivity measured for each sample at different temperatures.

\section{Figure 2 here}


It can be observed that all non-carbonaceous electrodes exhibit conductivity values in the same range that standard Vulcan carbon electrode, which means that all samples present adequate values to be used in HT-PEMFCs. The higher is the TiC content in the $\mathrm{SiCTiC}$, the higher is the electrical conductivity, which means that $\mathrm{TiC}$ has a positive effect on the performance of the material, in terms of decreasing of the ohmnic resistance. This fact is also demonstrated by the increasing of the conductivity values respect with the pure $\mathrm{SiC}$ as MPL values, achieved in previous studies [17].

As it has been pointed out previously, high stability of the components of the HTPEMFC is a challenge, especially if it is taken into account the harsh operation conditions during HT-PEMFC performance, which combines acidic environment and high temperature. In order to assess the stability from the viewpoint of the high temperatures that undergo these systems, the MPLs studied were subjected to a thermal treatment in hot acidic media. The samples were weighed to determine weight loses associated with the degradation of materials and no changes in the weight were found.

XRD were performed to the MPLs before and after the thermal treatment, shown in Figure 3, in order to detect changes on the crystallite structure of the materials related to the corrosion of the MPL or the electrode.

\section{Figure 3 Here}

It is very noticeable the apparition of a new peak around $2 \theta=26^{\circ}$ on all MPL patterns, compared with the powder patterns of figure 1 . These peak, as it can be observed comparing with Vulcan carbon based MPL electrode, is attributed to the main carbon peak of the carbon paper used as GDL [17]. SiCTiC with TiC molar content of 10 and $20 \%$ based MPL electrodes shown negligible changes in their GDL carbon peak, which could mean that the carbon paper surface is adequate covered by the MPL. The rest of 
peaks, attributed to the different faces of $\mathrm{SiC}$ and $\mathrm{TiC}$ also did not suffer important changes ( $\mathrm{L}_{c}$ parameter calculated for main $\mathrm{SiC}$ and $\mathrm{TiC}$ peaks changed around 1.2 and $0.8 \%$ respect to the fresh electrodes, respectively), being slightly more stable the electrode prepare with $\mathrm{SiCTiC} 20 \%$ mol. TiC, with could be attributed to its lower BET area compared with SiCTiC with lowest TiC content. This fact suggests that these both samples may be chemically stable under hot acidic corrosion environment of the HTPEMFC based on PBI membranes. On the other hand, Vulcan carbon based MPL exhibit an important decrease on the intensity of the main carbon peak (more than $12 \%$ Lc parameter variation between fresh and degraded electrode) which means that structural changes on the crystallinity of the material occurs, caused by the carbon corrosion. Finally, SiCTiC 30\% mol. Ti based electrode exhibit a high stability on the main MPL associated peaks ( $\mathrm{SiC}$ or $\mathrm{TiC}$ ones), but the main carbon peak of the carbon GDL shows a decreasing in their intensity, exhibiting an $8 \% \mathrm{~L}_{\mathrm{c}}$ of carbon crystal size variation, which suggest that in this case, MPL prepared with this material could not have covered properly all the electrode surface. This fact could be due to the high density of the SiCTiC with $30 \%$ TiC content, which means that the thickness of the MPL prepared with this material should be lower than the other MPLs prepared with the SiCTiC materials with 10 and $20 \%$ TiC molar content, and the covering of the GDL surface could be not perfect.

Electrochemical stability of the samples was studied by a voltammetric study. Figure 4 shows the same test performed to different electrodes with MPLs prepared with SiCTiC with 10, 20 and 30\% TiC mol. content, using a SiCTiC load of $4 \mathrm{mg} \mathrm{cm}^{-2}$. Results show that, as in the thermal studies, all SiCTiC materials exhibit similar behaviour under the electrochemical test, presenting an excellent stability, with negligible changes in the shape of the voltammograms during the test. No new peaks or changes on the shape of 
the cycles were observed during the test, which means that the surface of the material did not suffer changes. Changes occurred on the oxygen evolution in all samples could be due to a stabilization of the electrode surface during the first 100 cycles, and changes on the oxygen solved in the media, due to changes in the $\mathrm{N}_{2}$ inertization process caused by bubbling rate variations. XRD test were performed to evaluate changes on the crystallite structure, and no several changes were found in the crystal size of the main carbon, $\mathrm{SiC}$ and $\mathrm{TiC}$ peaks after the test (around $1.4 \%$ for main carbon peak and lower than $1 \%$ for SiC main peak). SiCTiC 20\% and 30\% mol. content based MPLs presented the same range of crystal size evolution, around $1 \%$ of carbon peak changes, lower than $0.7 \%$ in the case of $\mathrm{SiC}$ crystal size, which means that the $\mathrm{TiC}$ content does not have a significant influence on this parameter. In this case, no signs of degradation were noticed in the carbon peak of the $\mathrm{SiCTiC} 30 \%$ mol. TiC based electrode, which confirms that the cause of the degradation observed in the previous test could be due to an irregular deposition of the MPL prepared with this material.

Furthermore, due to the decreasing of the BET area, the double layer contribution of SiCTiC based electrodes containing higher amounts of $\mathrm{TiC}$ decreasing is very noticeable (1 magnitude order), as it can be observed in figure 4 .

\subsection{Catalyst evaluation}

According to the procedure described in the experimental section, actual Pt \%wt. content was determined by ICP method for all catalyst prepared. The results are shown in Table 2.

It can be observed that all catalysts exhibit similar Pt content respect to the nominal one, except in the case of the catalysts prepared on $\mathrm{SiCTiC} 30 \%$ mol. TiC. In this case, the actual platinum amount was lower than the nominal, which means that probably the low 
surface area and porosity of these materials avoid the correct deposition of all platinum during the synthesis process.

\section{Table 2 Here}

Figure 5 shows the XRD patterns of the different Pt/SiCTiC based material catalysts with a $40 \%$ wt. Pt content. No changes were observed for $\mathrm{TiC}$ or $\mathrm{SiC}$ peaks respect to the peaks observed in the support patterns, indicating that the $\mathrm{SiCTiC}$ crystallite structure remains stable during the catalyst deposition process. Thus, the other peaks at $2 \theta$ values of $39.6^{\circ}$, 46. $1^{\mathrm{o}}, 67.4^{\mathrm{o}}$ correspond to $\mathrm{Pt}(111), \mathrm{Pt}(200)$ and $\mathrm{Pt}$ (220) planes, respectively, being observed in all samples, which confirms the successfully Pt deposition. The platinum peaks are assigned according to the International Centre for Diffraction Data PDF 00-004-0802 and show a face-centered-cubic crystal structure for platinum. Moreover, at $39.6^{\circ}$, the peak associated to the $\mathrm{Pt}$ (111) face exhibits a double peak shape, which is probably related to the fusion of this $\mathrm{Pt}$ (111) peak with the peak related to the $\mathrm{SiC}(200)$ plane, which appears at $2 \theta$ $=41.3^{\circ}$. For this reason, the average platinum crystallite size was calculated from Pt (200) plane using the Scherrer formula. This Pt (200) plane is used very often to calculate the crystallite size of Pt based catalysts $[18,19]$.

\section{Figure 5 here}

Table 2 shows the Pt crystallite size of the different catalyst manufactured. All catalysts prepared with non-carbonaceous based materials exhibit large Pt crystal and particle size than commercial catalyst, as it was expected due to their lower BET area, which avoid the large dispersion of the platinum particles along the catalyst support. It can be observed that the agglomeration of the $\mathrm{Pt}$ is very remarkable in the case of the catalyst prepared with $\mathrm{SiCTiC}$ with $30 \%$ mol. TiC, which confirms the influence of the BET area on this parameter. 
In order to get more information about the Platinum dispersion, TEM micrographs were performed to the different catalysts, which are shown in Figure 6.

\section{Figure 6 here}

It can be observed that the effect of the support on the particle size shows a clear influence because the difference between the catalysts based on Vulcan carbon and binary carbide is significant. Table 2 shows the values of the average Pt particle size obtained for each catalyst, by counting 80 particles of each catalyst. The commercial catalyst shows the smallest particle sizes, as it was expected due to the large BET area. Initially, this result indicates that the active surface of the catalyst is expected to be higher in the case of the catalyst with the carbonaceous support material because of the lower size of the catalyst particles and the more efficient distribution associated with this lower size. It can be said that these results are in agreement with those obtained from the XRD analyses, comparing the crystal size and the particle size results, being sizes calculated by TEM slightly higher than crystal size values. Although, the average platinum particle sizes are higher than those obtained by XRD. Thus, the Pt particles deposited on the different SiCTiC materials exhibit sizes between 7 and $8 \mathrm{~nm}$, whereas the size of the commercial Pt particles deposited on the Vulcan carbon was around $3.5 \mathrm{~nm}$. These large Pt particle size values achieved for SiC-based catalyst are similar that achieved by other authors [20]. It must be pointed that the dispersion for the platinum particles obtained SiCtiC materials with 20 and 30\% mol. TiC was worse than the dispersion achieved for $\mathrm{SiCTiC}$ with $10 \%$ mol. TiC content, as it can be observed in Figures 6A,6B and 6C, probably due to the smaller BET area of these materials.

To get more information about the oxidation state of the platinum particles of the catalysts, TPR analysis were carried out to the different $40 \%$ wt. Pt content catalysts prepared. Figure 7 shows the different spectra obtained.

\section{Figure 7 here}


The SiCTiC support spectra does not present any hydrogen absorption peak in studied temperature region studied, just a very small peak appears in the 500-800 which could be related to small amounts of $\mathrm{TiO}_{2}$ or negligible hydrogen absorption process performed by the support [21, 22]. In the case of the $\mathrm{SiCTiC}$ based catalyst, especially using $\mathrm{SiCTiC}$ with 20 and $30 \%$ mol. TiC as support, a small peak appears at temperatures around $100{ }^{\circ} \mathrm{C}$, which could be attributed to the reduction of pure platinum precursor rests on the surface of the catalyst. On the second region, between 300 and $550{ }^{\circ} \mathrm{C}$, another 2 peaks appear at 320 (for $\mathrm{Pt} / \mathrm{SiCTiC} 20 \%$ and $30 \% \mathrm{TiC}$ mol content catalysts) and $450{ }^{\circ} \mathrm{C}$ (for Pt/SiCTiC $10 \% \mathrm{TiC} \mathrm{mol}$ content), which corresponded to the reduction of Pt complex and Pt oxides bounded to the surface of the catalyst support, respectively [21-23]. The peak located at $450{ }^{\circ} \mathrm{C}$ is also observable in the commercial catalyst, which means that in this catalyst the reduction of the platinum during the synthesis process is not also completed. At $550{ }^{\circ} \mathrm{C}(\mathrm{Pt} / \mathrm{SiCTiC} 20 \% \mathrm{~mol}$. $\mathrm{TiC})$ and $640{ }^{\circ} \mathrm{C}(\mathrm{Pt} / \mathrm{SiCTiC} 30 \% \mathrm{~mol}$. TiC) approx. a new peak appear, which could be attributed to the reduction of PtO strongly bounded to the support [21-23]. The shift of this peak among the different catalysts could be attributed to the different bounding forces of the Pt particles with the support, being higher for the $\mathrm{SiCTiC}$ with $20 \% \mathrm{TiC}$ molar content, probably due to their high surface compared with $\mathrm{SiC}$ and $\mathrm{SiCTiC} 30 \% \mathrm{~mol}$. TiC content. The last peak, appeared at $700-800{ }^{\circ} \mathrm{C}$ region in all materials, but specially for the $\mathrm{Pt} / \mathrm{Vulcan}$ catalyst, could be attributed to the reduction of Si or Ti oxides in the case of non-carbonaceous materials, and $\mathrm{CO}_{2}$ for the carbonaceous one, conducted by the presence of the Pt particles $[21,22]$. As it was pointed out, the oxidation of the carbonaceous support conducted by the platinum particles supported on it is especially remarkable, according to the size of the peak observed. On the other hand, $\mathrm{SiCTiC} 10 \% \mathrm{TiC}$ based catalyst exhibit the lowest area in its platinum oxides peaks, exhibiting not presence of peaks at 100 and $600{ }^{\circ} \mathrm{C}$, which means that the platinum reduction on this support was especially efficient. 
Finally, in order to evaluate the electrochemical behavior of the different catalysts, a voltammetric study was carried out on different electrodes manufactured with the same method that is used to prepare these catalysts into a half cell system, same that for the electrochemical support studies, but in this case, as it was pointed out in the experimental section, the temperature of the test was fixed in $50{ }^{\circ} \mathrm{C}$ instead of $25^{\circ} \mathrm{C}$, in order to increase the degradation of the samples and decrease the solutility of the gaseous Oxygen in the electrolyte, in order to appreciate better the Hydrogen desorption peak.. Figure 8 shows the voltammograms of various cycles, which compare the performances of the different catalysts prepared, containing the same platinum concentration (nominal content: $40 \% \mathrm{wt}$ ) and $\mathrm{Pt}$ loading $\left(0.3 \mathrm{mg} \mathrm{Pt} \mathrm{cm}^{-2}\right)$ but different supports.

\section{Figure 8 here}

Firstly, it can be observed in first place an increasing of the current at the $0.6-1.0 \mathrm{~V}$ vs. $\mathrm{Ag} / \mathrm{AgCl}$ electrode region, due to the Platinum oxides formation [24]. This slope decreases in all cases during the experiment, due to the platinum deactivation processes, formation of platinum oxide layers that decrease the activity of the catalyst and migration of the platinum particles to the electrolyte, decreasing the intensity of this region. This fact could be observed also in the platinum reduction region, which appears at $0.5 \mathrm{~V}$ vs. $\mathrm{Ag} / \mathrm{AgCl}$. On the other hand, a decreasing of the intensity in the highest voltage region $(0.9-1.0 \mathrm{~V}$ vs $\mathrm{Ag} / \mathrm{AgCL}$ electrode) can be observed only in the initial voltammograms of the SiCTiC based catalysts, attributed to the formation of Si and Ti oxides passivate layers, which present lower electrical conductivity, decreasing the maximum current peak achieved. The thickness and shape of the double layer does not suffer several changes in the non-carbonaceous materials, which means that these materials do not present important structural or chemical changes during the experiments, as it was shown in the previous electrochemical tests performed on the different supports studied in this work. The variations on the double layer in the $\mathrm{Pt} / \mathrm{SiCTiC}$ with $30 \%$ TiC mol. content, and the slight changes for the double layer observed in $\mathrm{Pt} / \mathrm{SiCTiC}$ with $20 \%$ 
mol TiC content, are attributed to a failure in the $\mathrm{N}_{2}$ supply to the cell during the last cycles of the test, which caused and increasing on the $\mathrm{O}_{2}$ presence in the media, producing a shift on the shape of the voltammograms. It can be appreciated that the commercial Vulcan catalysts exhibited a slight decreasing of the double layer region (0.2-0.4 V), which means a slightly decreasing of the surface area, which could be due to the degradation of the carbonaceous support, since the oxidation of the support decreases the porosity and related with this fact, the surface area of the material $[25,26]$. The hydrogen absortion/desorption peaks appear at same potential region (-0.2/0.15 V vs $\mathrm{Ag} / \mathrm{AgCl}$ electrode). As it was pointed out in the support characterization, BET surface area of the materials has a clear effect to the double layer contribution of the materials in the cyclic voltammograms shapes. It can be observed that Pt/Vulcan carbon (184 $\mathrm{m}^{2} \mathrm{~g}^{-1}$ BET area) catalyst exhibits the best contribution to the double layer, while $\mathrm{Pt} / \mathrm{SiCTiC}$ based catalysts $\left(55,28\right.$ and $\left.12 \mathrm{~m}^{2} \mathrm{~g}^{-1}\right)$ present a lower contribution to double layer effect, especially in the voltage region located between 0.1 and $0.3 \mathrm{~V}$ vs $\mathrm{Ag} / \mathrm{AgCl}$. In addition, these BET area values are lower than BET areas of supports. The surface area decreasing percentage is directly related with the Pt loading on the catalysts (around $40 \%$ in the case of non-carbonaceous materials, obtaining BET decreasing around 44 $\%$ for $\mathrm{SiCTiC}$ based catalysts, and $34.5 \%$ in the case of commercial catalyst), which asseverates the successfully Pt deposition in all cases.

Respect to the orientation of the platinum particles, it can be observed that in the case of those supported on the SiCTiC materials with higher amounts of $\mathrm{TiC}$ are divided between ( $\left.\begin{array}{lll}1 & 0 & 0\end{array}\right)$ and $\left(\begin{array}{lll}1 & 1 & 1\end{array}\right)$ faces $[27,28]$, attending to the presence of two $\mathrm{H}_{2}$ desorption peaks. In the case of Pt deposited on SiCTiC with $10 \%$ mol. TiC, the division of the crystalline plane orientation is less evident, with a preferent orientation to the $\left(\begin{array}{lll}1 & 0 & 0\end{array}\right)$ face. In the case of the commercial catalyst, $\mathrm{Pt} / \mathrm{C},\left(\begin{array}{lll}1 & 0 & 0\end{array}\right)$ orientation is the most observed, presenting only one hydrogen desorption peak. Using the area of these desorption peaks, ECSA values were calculated for each catalyst for cycles 1 and 400, using the equation 4 . The obtained values 
are shown in Table 3, where the degradation of the catalysts in terms of the ECSA degradation is also shown.

\section{Table 3 here}

It can be observed that $\mathrm{SiCTiC}$ with $10 \%$ mol. TiC catalyst exhibit higher ECSA values than commercial catalyst, but the platinum particles are also higher in SiCTiC catalysts. The higher double layer contribution effect in the case of Vulcan carbon catalyst could mask part of the $\mathrm{H}_{2}$ absorption/desorption peak, reducing the active area observed. It also remarkable that the $\mathrm{SiCTiC} 10$ and $20 \%$ mol. TiC based catalyst exhibit the lowest ECSA degradation, which could be due to the higher electrochemical stability of non-carbonaceous materials compared with Vulcan carbon $[17,26]$. On the other hand, the higher size of the platinum particles observed in the case of non-carbonaceous catalyst compared with the commercial one could improve the electrochemical stability of the catalyst, avoiding the agglomeration and migration processes of the platinum supported particles. Furthermore, it can be observed that the catalyst prepared using $\mathrm{SiCTiC} \mathrm{30 \%} \mathrm{mol.} \mathrm{Ti} \mathrm{as} \mathrm{catalyst} \mathrm{support,} \mathrm{as}$ it was expected taking into account the physicochemical characterization results, exhibited the worst performance and the highest degradation rate of all catalysts tested. The high ECSA losses could be attributed that, since the Pt has no adequate surface to bond to the support, is easily removed over the catalyst layer, traduced in a considerable reducing of the ECSA. The low ECSA values, as it was pointed out, and same in the case of the SiC catalyst observed in previous works carried out by our research group [29], is caused by the high agglomeration of the particles and the irregular distribution of the metallic particles through the surface of the support. Moreover, SiCTiC prepared with 10 and 20\% mol. TiC content exhibited similar results, being slightly more stable the catalyst prepared with $20 \%$ mol. TiC content, which suggest that the BET area of this material is enough to provide a good bond of the Pt particles to the support, and the lower surface area exposed prevents the degradation of the surface, avoiding the catalyst migration and agglomeration processes. 


\section{Conclusions}

In the present work, the influence of the TiC content in the properties of the binary carbide $\mathrm{SiCTiC}$ has been studied. From the obtained results, the following main conclusions have been attained.

- Surface area and electrical conductivity are the two most influenced parameters by the TiC content in the binary carbide. Surface area suffers a high decreasing if SiCTiC materials with $\mathrm{TiC}$ contents of 10 and $30 \%$ mol. are compared. On the other hand, the higher is the $\mathrm{TiC}$ content, the higher is the electrical conductivity of the material.

- The electrochemical and thermal resistance of the material is not be influenced for the TiC content, showing all materials excellent corrosion stability in acidic media.

- Due to their low surface area and porosity, SiCTiC with $30 \% \mathrm{TiC}$ content is not adequate to be used as catalyst support or raw material for microporous layer in HT-PEMFC.

- Platinum based catalyst prepared with $\mathrm{SiCTiC}$ with $10 \%$ mol. TiC exhibit the best active surface area, buth the Pt based catalyst prepared with SiCTiC with $20 \%$ mol. TiC has better stability. Further studies in fuel cell must be performed in order to evaluate the optimum value.

\section{Acknowledgements}

The authors further thank the European Commission as part of this work was supported by the Seventh Framework Programme through the project CISTEM (FCH-JU Grant Agreement Number 325262). 


\section{References}

[1] Q. Li, R. He, J.O. Jensen, R.F. Savinell, N.J. Bjerrum, Prog. Polym. Sci., 34, $2009,449-477$.

[2] J. B. d'Arbigny, G. Taillades, M. Marrony,b D. J. Jones and J.Rozie`re, Chem. Commun., 47, 2011, 7950-7952.

[3] S. Zhang, X.-Z. Yuan, J. N. C. Hin, H. Wang, K. A. Friedrich and M. Schulze, J. Power Sources, 194, 2009, 588-600.

[4] Y. Shao, G. Yin and Y. Gao, J. Power Sources, 171, 2007, 558-566.

[5] W. Schmittinger and A. Vahidi, J. Power Sources, 2008, 180, 1-14.

[6] D.A. Stevens, J.R. Dahn, Carbon 43, 2005, 179-188

[7] Lv HF, Mu SC, Cheng NC, Pan, M Appl Catal B-Environ, 2010, 100: 190-196

[8] B. Avasarala, T.Murray, W.Z.Li, P.Haldar, J. Mater. Chem.19, 2009, 1803-1805.

[9] S.B. Yin, S.C. Mu, H.F. Lv, N.C. Cheng, M. Pan, Z.Y. Fu, Appl. Catal. B 93, 2010,233-240.

[10] S.Y. Huang, P. Ganesan, S. Park, B.N. Popov, J. Am. Chem. Soc. 131, 2009, 13898-13899.

[11] L. Dong, X. Tong, Y. Wang, X. Guo, G. Jin, J Solid State Electrochem 18, 2014, 929-934

[12] A. Deneuve, I. Florea, O. Ersen, P. Nguyen, C. Pham, D. Bégina, D. Edouard, M.J. Ledouxa, C. Pham-Huu, Applied Catalysis A: General 385, 2010, 52-61

[13] R. Dhiman, S. N. Stamatin, S. M. Andersen, P. Morgen, E. M. Skou, J. Mater. Chem. A 1, 2013, 15509-15516

[14] J. Lobato, H. Zamora, J. Plaza, M. A. Rodrigo, Chemcatchem 8, 2016, 848-854

[15] J. Lobato, P. Cañizares, M.A. Rodrigo, D. Úbeda, F.J. Pinar, J.J. Linares, Fuel

Cells $10(2010) 770-777$

[16] P. Nguyen, C. Pham, Applied Catalysis A: General, 391 (2011) 443-454

[17] J. Lobato, H. Zamora, P. Cañizares, J. Plaza, M.A. Rodrigo, Journal of Power Sources 288, 2015, 288-295 
[18] J. Lobato, P. Cañizares, M.A. Rodrigo, J.J. Linares, Applied Catalysis B:

Environmental 91 (2009) 269-274.

[19] J. Lobato, P. Cañizares, D. Ubeda, F.J. Pinar, M.A. Rodrigo, Applied Catalysis

B: Environmental 106 (2011) 174-180.

[20] S.N. Stamarin, J. Speder, R. Dhiman, M. Arenz, E.M. Skou, ACS Appl.Mater. Interfaces 7 (2015) 6153-6161

[21] S.R de Miguel, O.A. Scelza, M.C. Román-Martínez, C. Salinas-Martínez de Lecea, D. Cazorla-Amorós, A. Linares-Solano, Applied Catalysis A: General 170 (1998) 93-103

[22] M.A. Aramendía, J.C. Colmenares, A. Marinas, J.M. Marinas, J.M. Moreno, J.A. Navío, F.J. Urbano, Catalysis Today 128 (2007) 235-244

[23] G.C. Torres, E.L. Jablonski, G.T. Baronetti, A.A. Castro, S.R. de Miguel, O.A. Scelza, M.D. Blanco, M.A. Pefia Jimenez, J.L.G. Fierro, Applied Catalysis A: General 161 (1997) 213-226

[24] T. Reier, M. Oezaslan, P. Strasser. ACS Catal. 2 (2012) 1765-1772.

[25] H. Zamora , P. Cañizares , M.A, Rodrigo, J. Lobato, Fuel Cells 15(2) (2015) $375-383$.

[26] F. Büchi, N. Inaba, T.J. Schmidt, Polymer Electrolyte Fuel Cell Durability, Springer Science + Business Media 2009

[27] Q.He, X. Yang, W. Chen, S. Mukerjee, B. Koel, S. Chen, Phys. Chem. Chem. Phys. 12 (2010) 12544-12555.

[28] K. Kinoshita, J. Electrochem. Soc. 137 (2010) 845-848.

[29] J. Lobato, H. Zamora, J. Plaza, P. Cañizares, M. A. Rodrigo, Applied Catal. B: Environmental 198 (2016) 516-524 
Table 1. Surface area and porosity data obtained from BET and XRD analysis

Support SiCTiC 10\% mol TiC SiCTiC 20\% mol TiC SiCTiC 30\% mol TiC

\begin{tabular}{cccc}
\hline $\begin{array}{c}\text { Surface Area } \\
\left(\mathbf{m}^{2} / \mathbf{g}\right)\end{array}$ & 99.5 & 55.4 & 23.2 \\
$\begin{array}{c}\text { Micropore } \\
\text { Volume (cc/g) }\end{array}$ & 0.008 & 0.001 & 0.000 \\
$\begin{array}{c}\text { Total pore } \\
\text { volume (cc/g) }\end{array}$ & 0.175 & 0.189 & 0.110 \\
$\begin{array}{c}\text { Average Pore } \\
\text { diameter (nm) }\end{array}$ & 4.1 & 6.9 & 9.5 \\
$\begin{array}{c}\text { Crystallite size } \\
\text { (nm) }\end{array}$ & $28.0\left(2 \theta=36.0^{\circ}\right)$ & $20.8\left(2 \theta=35.6^{\circ}\right)$ & $23.9\left(2 \theta=35.6^{\circ}\right)$ \\
$\begin{array}{c}\text { Distance } \\
\text { between } \\
\text { planes }(\mathbf{n m})\end{array}$ & $0.252\left(2 \theta=35.6^{\circ}\right)$ & $0.2252\left(2 \theta=35.6^{\circ}\right)$ & $0.252\left(2 \theta=35.6^{\circ}\right)$ \\
\hline
\end{tabular}


Table 2. Pt content, Pt crystallite sizes obtained from XRD analyses, Average Pt particle size determined from TEM micrographs and BET values of the supports for the different catalyst evaluated

\begin{tabular}{|c|c|c|c|}
\hline Catalyst & $\begin{array}{c}\text { Real Pt } \\
\text { Content } \\
\text { [\% wt.] }\end{array}$ & 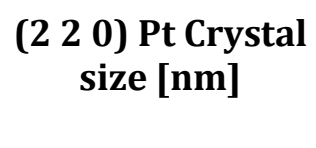 & $\begin{array}{c}\text { Average Pt particle } \\
\text { size }[\mathrm{nm}]\end{array}$ \\
\hline $\begin{array}{l}40 \% \mathrm{Pt} / \mathrm{SiCTiC} \\
(10 \% \mathrm{~mol} . \mathrm{TiC})\end{array}$ & $40.3 \pm 0.5$ & 6.5 & $7.0 \pm 0.6$ \\
\hline $\begin{array}{l}40 \% \mathrm{Pt} / \mathrm{SiCTiC} \\
(20 \% \mathrm{~mol} . \mathrm{TiC})\end{array}$ & $39.7 \pm 0.4$ & 7.1 & $7.3 \pm 0.7$ \\
\hline $\begin{array}{l}\text { 40\% Pt/SiCTiC } \\
\text { (30\% mol. TiC) }\end{array}$ & $37.5 \pm 0.7$ & 7.1 & $7.7 \pm 0.5$ \\
\hline $\begin{array}{c}40 \% \mathrm{Pt} / \text { Vulcan } \mathrm{XC}-72 \\
\text { (commercial) }\end{array}$ & $40.2 \pm 0.3$ & 4.2 & $3.6 \pm 1.1$ \\
\hline
\end{tabular}


Table 3. ECSA values at different cycles for all catalyst tested in half-cell studies.

\begin{tabular}{|c|c|c|c|}
\hline Catalyst & $\begin{array}{c}\text { ECSA (Cycle 1) } \\
\qquad\left(\mathrm{m}^{2} \mathrm{~g}^{-1}\right)\end{array}$ & $\begin{array}{c}\text { ECSA (Cycle 400) }\left(\mathrm{m}^{2}\right. \\
\left.\mathrm{g}^{-1}\right)\end{array}$ & ECSA degradation (\%) \\
\hline $\begin{array}{r}40 \% \text { Pt/SiCTiC } \\
\text { mol. Ti })\end{array}$ & 38.80 & 31.70 & 18.30 \\
\hline $\begin{array}{c}40 \% \mathrm{Pt} / \mathrm{SiCTiC} \\
\mathrm{mol} . \mathrm{Ti})\end{array}$ & 23.76 & 20.08 & 15.49 \\
\hline $\begin{array}{r}40 \% \text { Pt/SiCTiC } \\
\text { mol. Ti })\end{array}$ & 4.37 & 2,72 & 37.58 \\
\hline $\begin{array}{l}\text { Commercial } \\
(40 \% \mathrm{Pt} / \mathrm{C})\end{array}$ & 29.35 & 19.48 & 33.61 \\
\hline
\end{tabular}




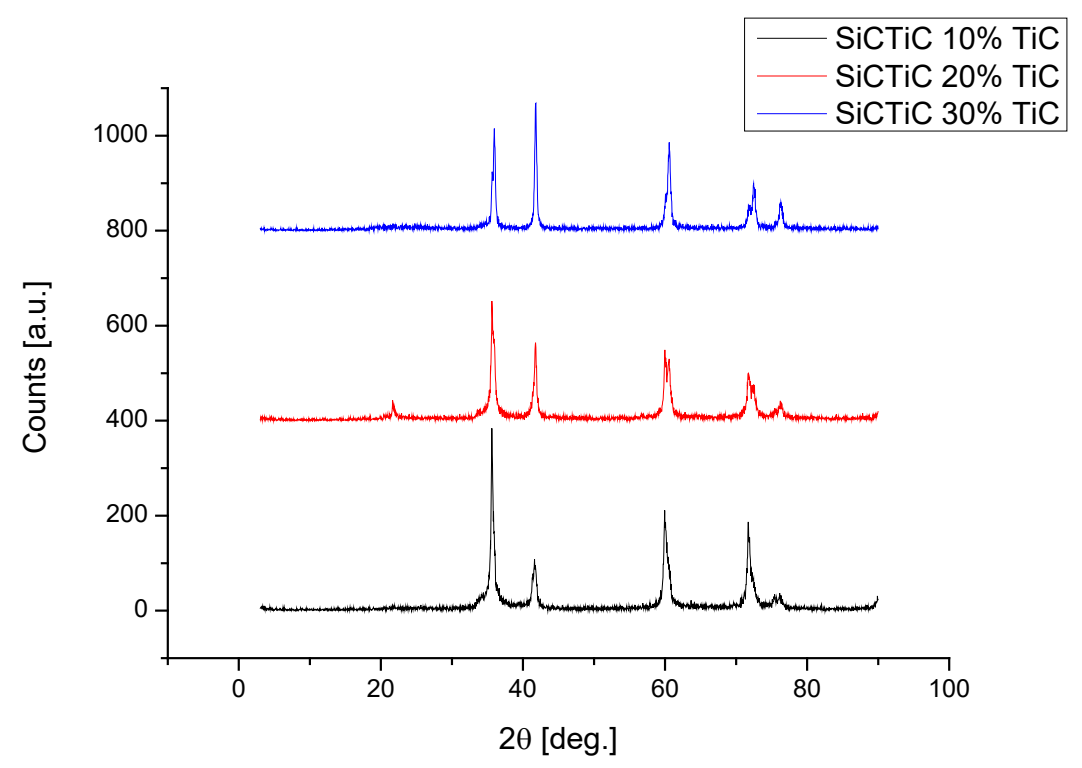

Figure 1. XRD measurements of $\mathrm{SiCTiC}$ with diffferent $\mathrm{TiC}$ amount 


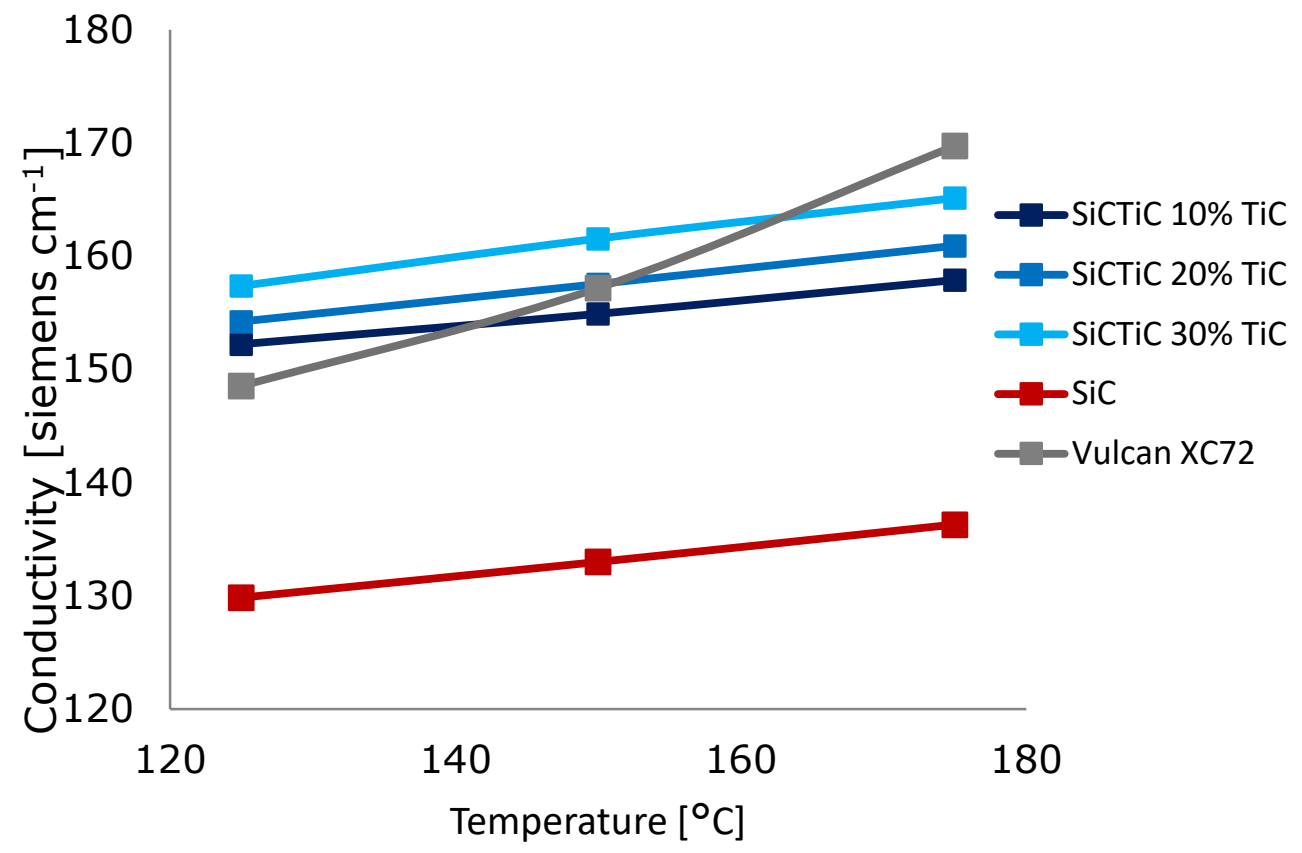

Figure 2. Comparison of electrical conductivity for electrodes prepared with different MPLs 

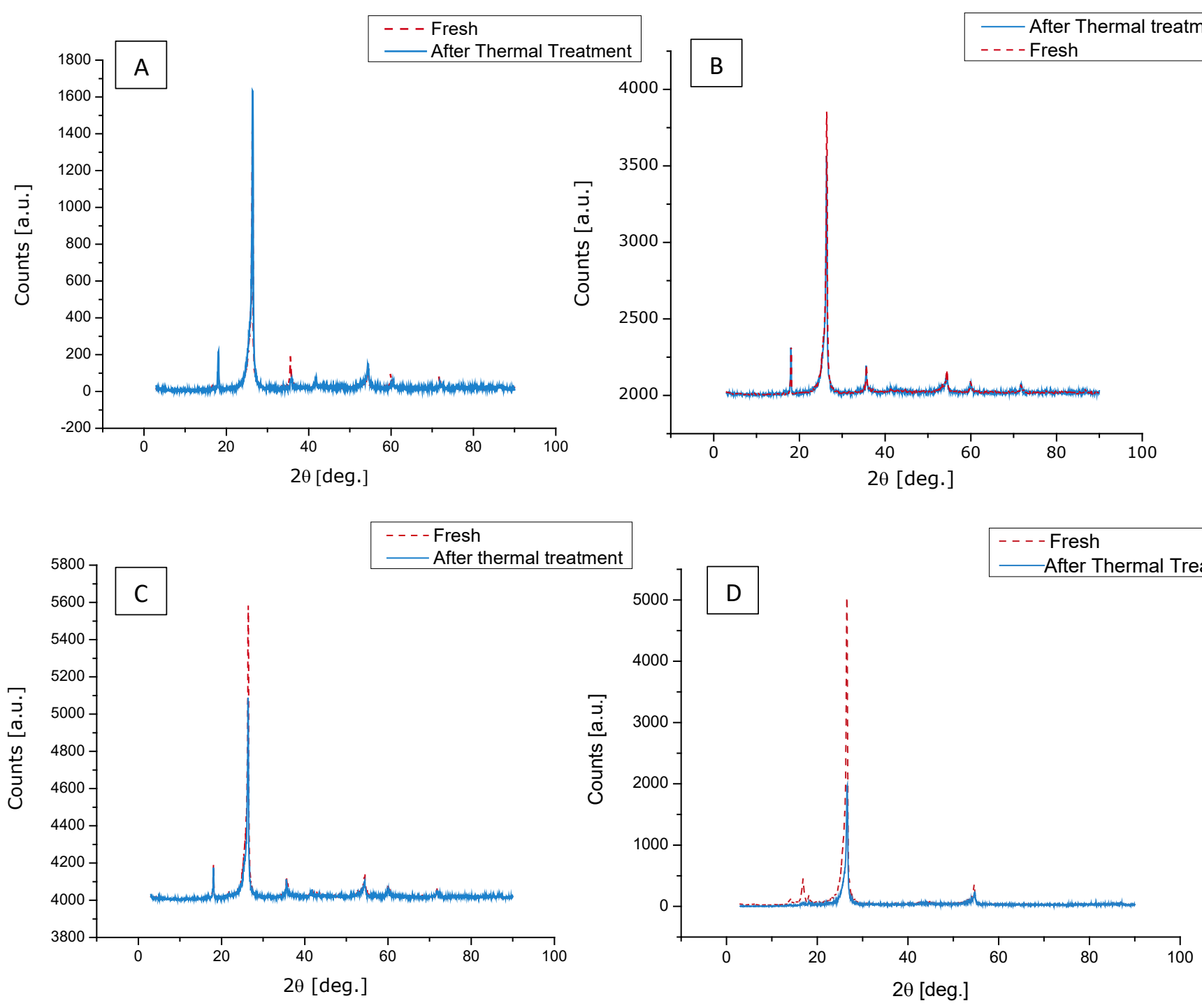

Figure 3. XRD patterns before and after the thermal stability study of different MPLs. A) SiCTiC $10 \%$ mol. Ti (4 mg cm${ }^{-2}$; B) SiCTiC $20 \%$ mol. Ti (4 $\left.\mathrm{mg} \mathrm{cm}^{-2}\right)$; C) SiCTiC $30 \%$ mol. Ti (4 $\left.\mathrm{mg} \mathrm{cm}^{-2}\right)$; D) Commercial GDL + Vulcan XC72 MPL (2 $\left.\mathrm{m} \mathrm{cm}^{-2}\right)$ 

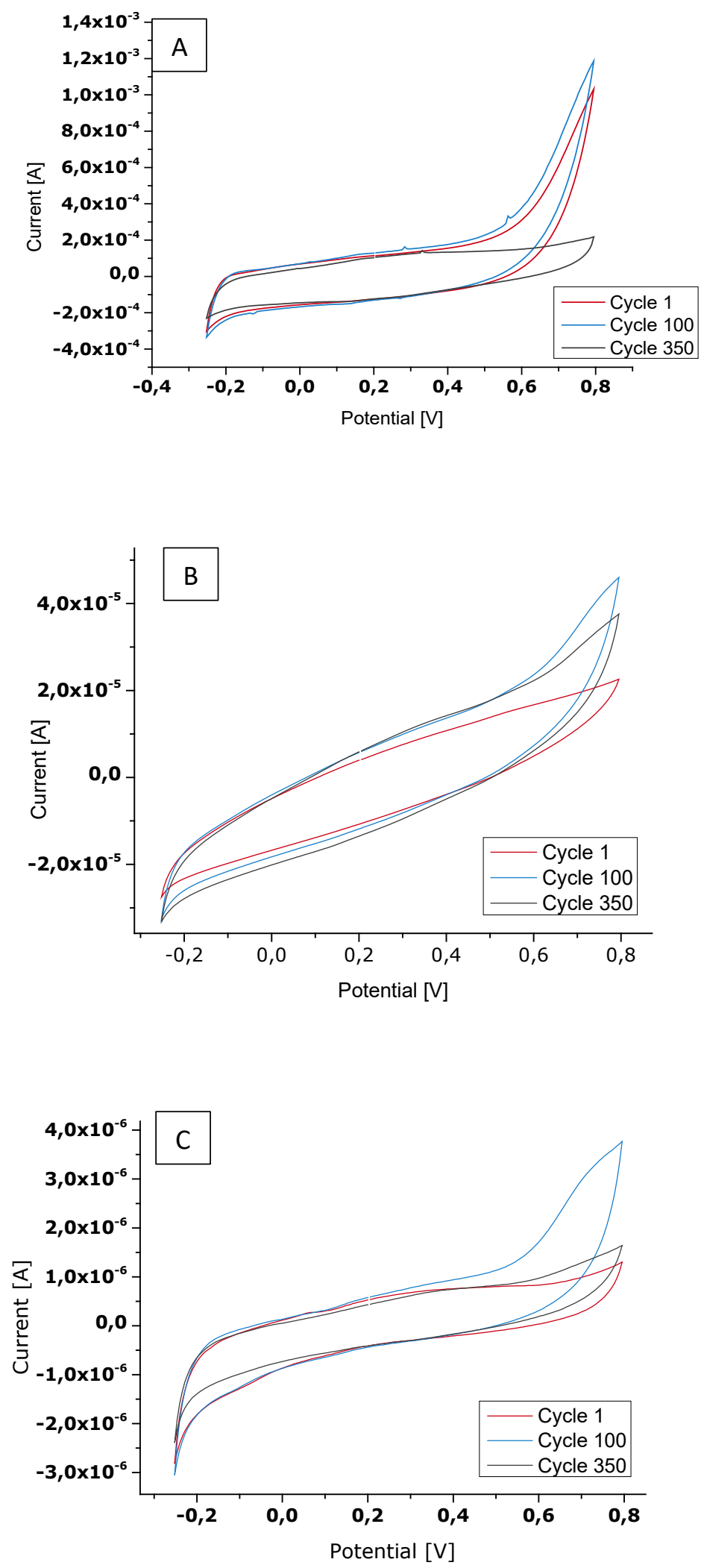

Figure 4. Evolution of the cyclic voltammograms during the electrochemical stability test for different SiCTiC based MPLs (SiCTiC load $4 \mathrm{mg} \mathrm{cm}^{-2}$ ): A) SiCTiC 10\% mol. content; B) $\mathrm{SiCTiC} 20 \%$ mol. content; and C) SiCTiC 30\% mol. content. 


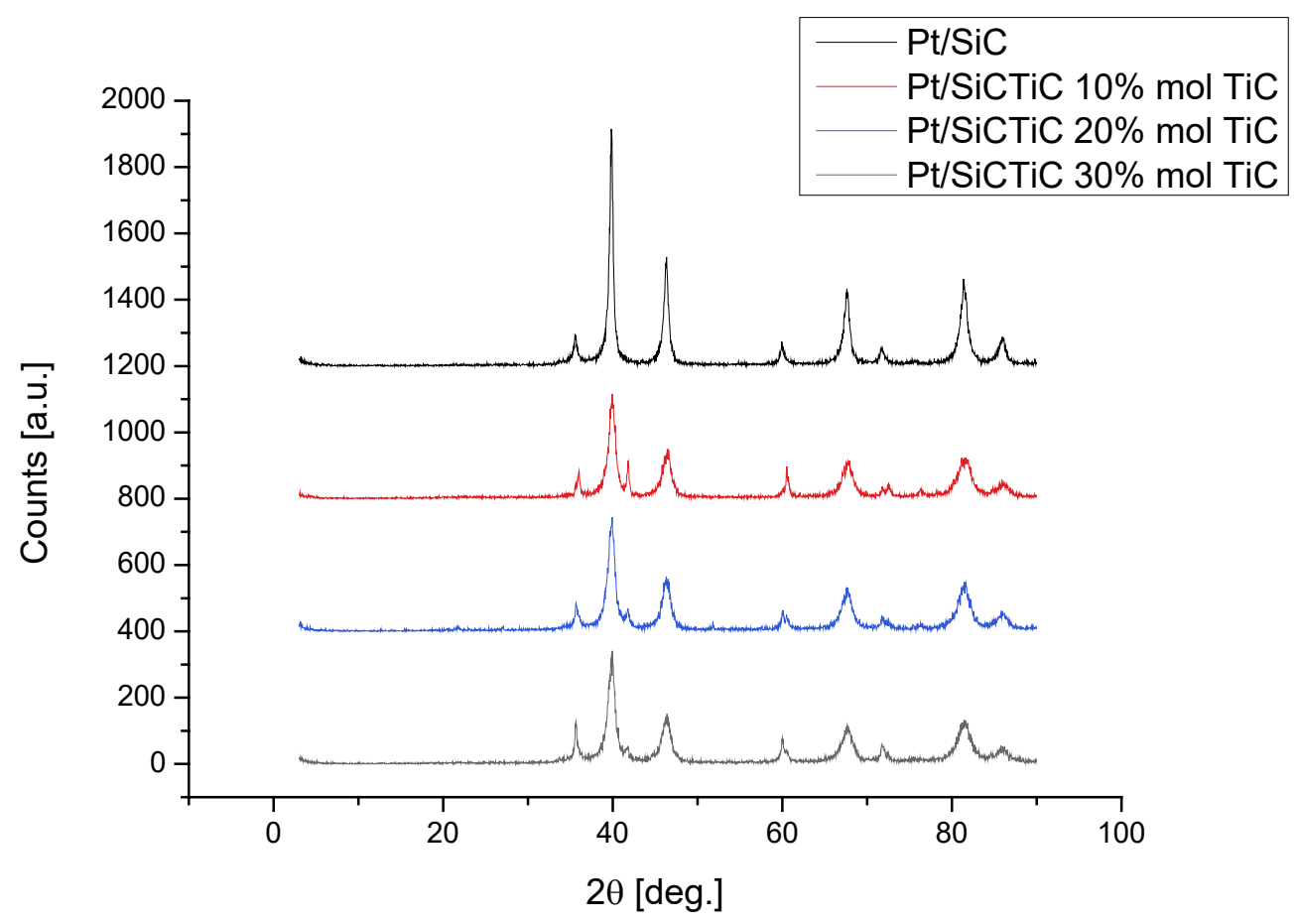

Figure 5. XRD patterns obtained for the different $40 \%$ wt. Pt SiCTiC based catalysts prepared. 

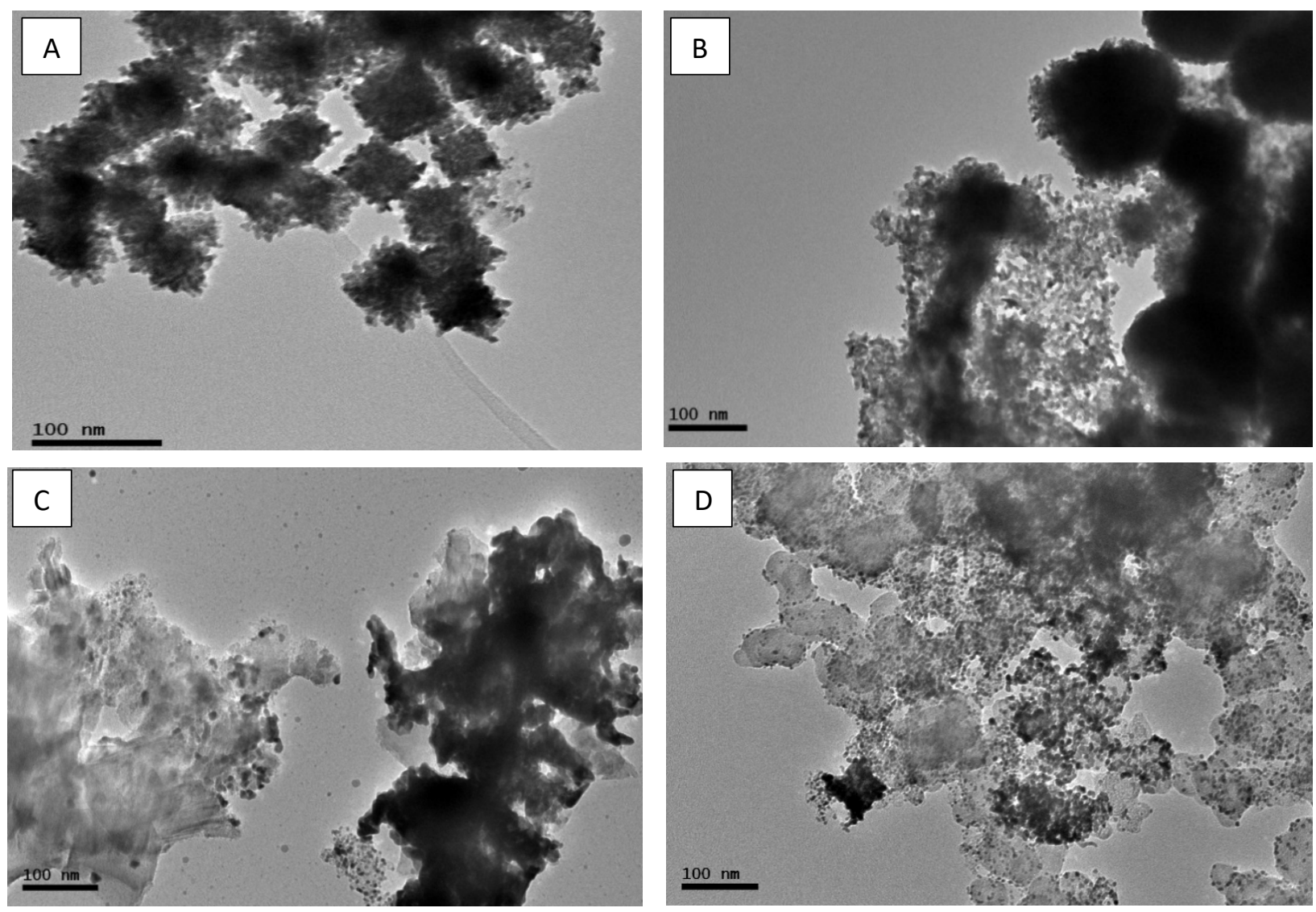

Figure 6. TEM micrographs of different catalyst: A), B), and C) 40\% Pt supported on SiCTiC with 10, 20 and 30\% mol. Ti content, respectively; D) Commercial catalyst $40 \%$ wt. Pt/Vulcan. 


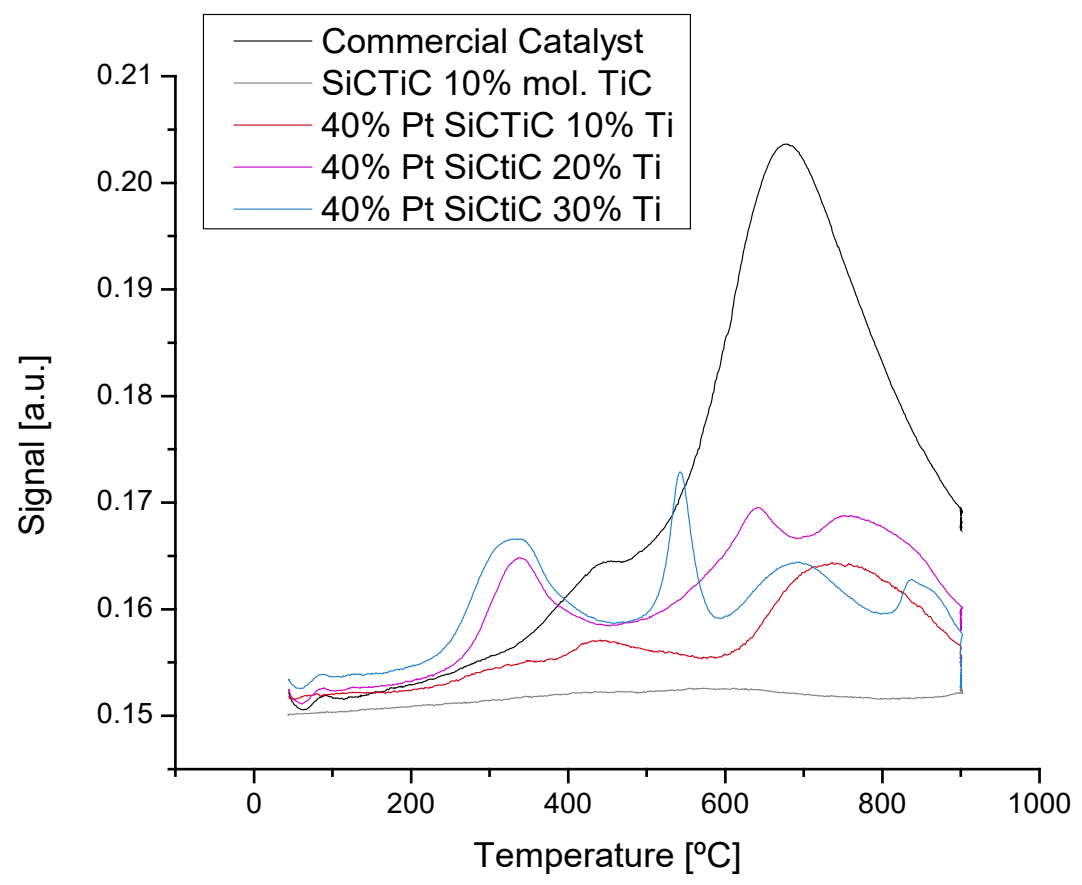

Figure 7. TPR spectra for SiCTiC support, different Pt/SiCTiC based catalyst and commercial Pt/Vulcan Catalyst. 

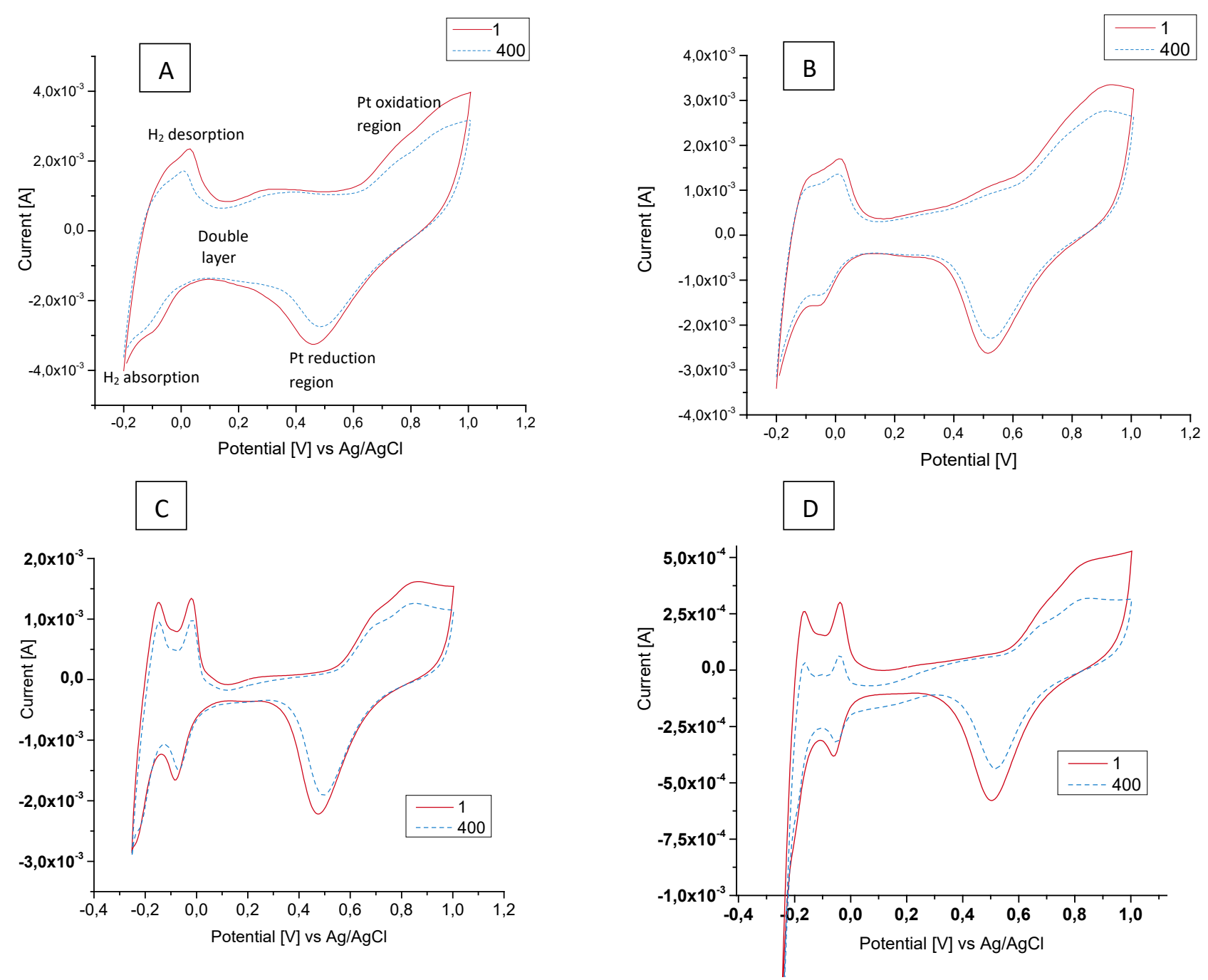

Figure 8. Cycle 1 and 400 voltammograms of different catalyst tested: A) Commercial catalyst; B), C), and D) 40\% wt. Pt/SiCTiC 10, 20 and 30\% mol. TiC content, respectively 